\title{
A SYSTEMS APPROACH TO ANALYSING WORK EFFICIENCY IN POWER CONTROL ROOMS: A CASE STUDY
}

\author{
G.L. Janackovic ${ }^{1} \&$ M.D. Grozdanovic ${ }^{2}$
}

\section{ARTICLE INFO}

Article details

Submitted by authors 6 Mar 2020

Accepted for publication 24 Aug 2020

Available online 14 Dec 2020

Contact details

Corresponding author

goran.janackovic@znrfak.ni.ac.rs

\section{Author affiliations}

1 Chair of System Research in Safety and Risk, Faculty of Occupational Safety, University of Nis, Serbia

2 Department of Electrical Engineering, Engineering Academy of Serbia, Serbia

\section{ORCID® identifiers}

G.L. Janackovic

https: //orcid.org/0000-0001-9481-0183

M.D. Grozdanovic

https://orcid.org/0000-0002-7702-7434

\section{DOI}

http://dx.doi.org/10.7166/31-4-2277
The research model presented in this article, of control room operators' work activities in an electric power system, includes an analysis of the main control room's characteristics, the performance of the operators, and the influence of the environment on the operators' efficiency. For the purpose of group ranking the most important aspects describing the risk factors, fuzzy numbers are used. The influence of all the experts on the final decision is based on their previous experience. Human system, control information system, and supporting system elements are used as assessment criteria. In the analysed control room, the major impact on the operators' efficiency is the causes and effects of stress and the presentation of information. Display panels and control desks are crucial aspects of the control information system, as they affect the efficient presentation of information. In relation to the indoor environment, lighting conditions are identified as the most important. Based on the results obtained, we propose changes that decrease the risks by enabling better work positions for operators and the presentation of information on display panels and graphic screens.

\section{OPSOMMING}

'n Elektriese kragstelsel se beheerkameroperateurs se aktiwiteite word in hierdie artikel ontleed. Die analise sluit in die hoof beheerkamer se eienskappe, die vertoning van die operateurs en die invloed van die omgewing op hul doeltreffendheid. Wasige nommers word gebruik om die belangrikste aspekte wat die risikofaktore beïnvloed te rangskik. Die invloed van die kundiges op die finale besluit is gegrond op hul vorige ervaring. Mens-stelsel, beheer inligtingstelsel en ondersteuningstelsel elemente is gebruik as assesseringskriteria. Die hoof impak op operateurs in die bestudeerde beheerkamer se doeltreffendheid is die oorsake en gevolge van spanning en die aanbieding van inligting. Vertoonpanele en beheerlessenaars is kritiese aspekte van die beheer inligtingstelsel, omdat hulle die doeltreffende aanbieding van inligting beïnvloed. Beligting is ook identifiseer as belangrik. Veranderinge aan die hand van hierdie resultate word voorgestel om risiko's te verminder.

\section{INTRODUCTION}

The efficient and safe distribution of electric power needs effective monitoring and responsiveness. The operator is located in the control room, to which information from the field is transferred. The monitoring system provides the data on the current state of the distribution system and production units [1-3]. The speed and precision of the operator's decision-making are mainly influenced by the quality and completeness of the information that is received. In both modern and conventional electric power control rooms (CRs), the functions, architecture, indoor environment, and applied technologies are identified as the most important properties. Functional efficiency and the harmonisation of control information systems with the capabilities of the operators in the CRs are achieved at three different levels - perception, data processing, and action. By achieving such harmonisation, an operator can efficiently solve decision-making, diagnosis, and planning problems. The incorporation of ergonomic requirements into the system design improves the effectiveness of the monitoring system [4]. A detailed assessment of the operator and the control system elements is needed. As a result of the research, a detailed analysis of the operator's 
activities was obtained. This was the basis for the creation of a cognitive model incorporating complex cognitive activities such as prediction, monitoring, and mental calculations [5]. The design of many conventional CRs was made on the basis of the display panel installations, which defined the CR's dimensions, and the shape and dimensions of the control desks. By applying modern technologies, more data processing functions can be achieved with significant workspace savings. The issues regarding working conditions can be the cause of incorrect operator decisions and inappropriate reactions to adverse events. The humanisation of the working environment increases an operator's overall working abilities, which is especially important during shift work [6].

Risk analysis is needed, because many aspects influence the operators during their work and decisionmaking. Very important aspects of that analysis are, among others, organisation of the control room, the presentation of obtained information, and an analysis of the operator's activities [7]. Control room equipment helps an operator to monitor the electric power system and assess its state and reliability [1]. The integration of information reduces the time needed for decision-making, improves operational efficiency, and increases the efficiency of resource utilisation. It also improves the reliability of the system by better evaluations of the state of an electric power grid [8]. The development of the system and the control room, taking into account the efficiency of the operators, increases the success of the monitoring [7]. Improving the operators' working conditions can improve the accuracy of the decisions they make.

The activity of an operator is significantly influenced by the interaction between themselves and the CR equipment, as well as by their workload and situation awareness. There are different interactions between the operators and the CR equipment, because they must observe the functioning of the system and initiate corresponding safety actions [9, 10]. The workload and the CR design affect the accuracy and reliability of the operators' decisions [11]. Ergonomic design principles were therefore applied during the design of CRs and work systems. Because of the need for interaction, the human-centred principles of interaction were applied during the development of the CRs [12-15]. Efficient interaction improves the speed and the accuracy of the operator's reactions.

A subjective rating of the workload, fatigue, and stress of an operator is usually based on the collection of activity data and an analysis of their psychological load [16]. Illumination and the lighting conditions also affect the workload of an operator [17]. Alarm situations also require a physical or cognitive response in order to identify the anomaly and maintain the safe and efficient operation of the system [18].

The concept of 'situation awareness' is significant in human factor analysis in independent and collaborative energy production and distribution systems, where more attention must be paid to coordinated behaviour, collaborative tasks, training programmes, information searching tasks, performance defined by experience and training, and the definition of work procedures [19-21].

The ergonomic assessment of the activities of CR operators and the conditions in which these activities take place is needed to identify the most important determining factors: the reach of the operator's hands; the visual, muscular, and mental symptoms of fatigue; the technological obsolescence of CR elements; the locations and dimensions of the control panels; seat dimensions, and the dimensions and colours of the display panels; information capacity; the contrast between symbols and the graphic screen background, flickering, and the reflections of graphic screens, and colours on graphic screens; keyboard functionality; CR lighting; and microclimate.

The analysis of the complex system described here is based on the application of a systems approach and the fuzzy analytic hierarchy process. Since its initial development, the analytic hierarchy process (AHP) and fuzzy AHP (FAHP) have been applied in many areas in risk assessment, control room development, and process safety assessment - such as the assessment of the human-machine interface [22], estimating the risk of accidents [23], the quantitative estimation of human error probability [24], accident scenario risk assessment [25], and skill measurement and identification of the performance indicators of industrial operators [26, 27]. The procedure for decomposing the elements of a decision-making problem into smaller parts and a pairwise comparison of the elements with fuzzy numbers is used to define the priority of elements in the hierarchy of ergonomic research.

This paper presents the analysis of the CR of the Electric Power Company of Serbia. In applying an analysis of the system, the research into the ergonomics of this complex system is divided into the analysis of the operator, the control room, and the indoor environment. 
Human factors are an important aspect of situation assessment in power grid operations [28]. They must be included during the requirement specification and the definition of guidelines for control system development. Some future requirements and the possibility of further development of a system must also be considered [29]. In addition to the analysis of the human system, the research model is created according to a detailed analysis of the complex CR working environment, which consists of the control desk, the graphic screens, and the display panel (control information system), taking into account the lighting, noise, and microclimate (supporting system). The FAHP method, involving a pairwise comparison of all of the requirements, is applied.

\subsection{Research model}

The research model of a complex system, presented in Figure 1, consists of the system analysis and the system synthesis, providing optimal solutions to improving productivity in a complex system of ergonomic research.

Within the model, the following analyses were done: anthropometric, biomechanical, and sensorimotor analysis [30]; mental workload and situation awareness [31]; human reliability and stress assessment [32, 33]; cognitive task analysis [34]; ergonomic design [35-37]; information flow analysis [38]; microclimate conditions assessment and illumination measurement [39, 40]; and health and safety system assessment [41].

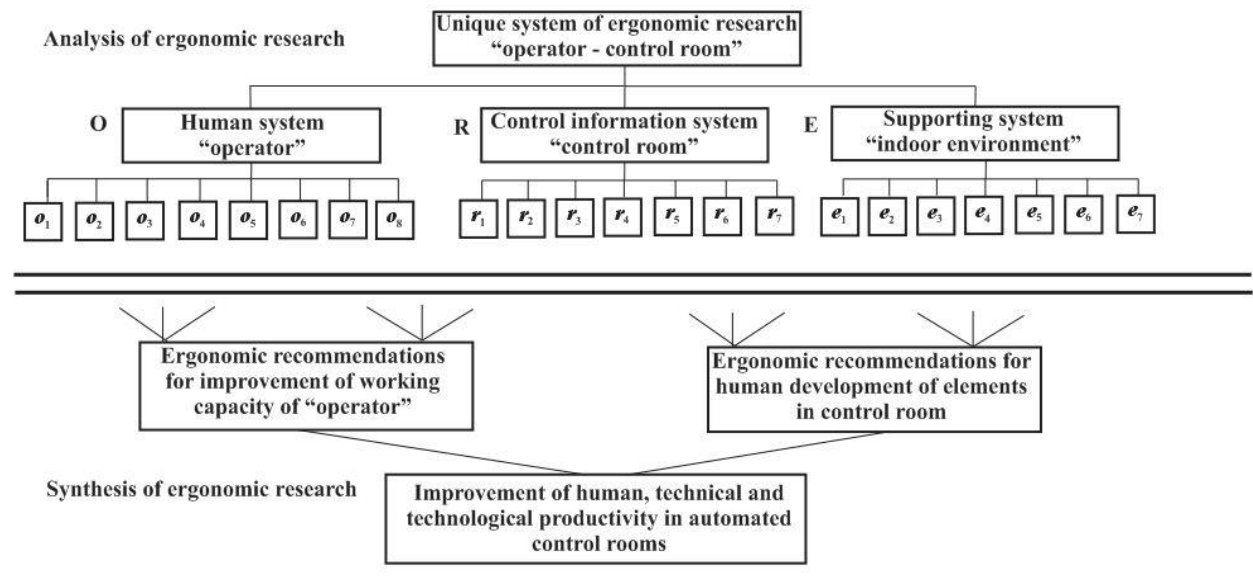

Figure 1: Ergonomic research in electric power control rooms

The analysis is based on the following research areas:

\section{O) Bio-cybernetic system 'dispatcher-operator'}

$\left(\mathrm{o}_{1}\right)$ Anthropometric measures. The anthropometric list, modified according to Grieko-Masalin (Appendix 2 in [42]), was used. The measurements were carried out using a Harpenden anthropometer (98601) on the population of 30 operators, and we obtained 20 anthropometric values for every operator. For this data, correlation coefficients, which define their mutual relationships, were calculated. SPSS version 22 was used to calculate the correlation coefficients representing the relationship strength between the relative movements of two variables. The value of correlation coefficient 1 defines the strongest relationship between anthropometric parameters, while the value 0 represents the weakest relationship [43, 44]. Based on this data, the dimensions of the characteristic body parts of the operators working at the control desk were determined (shoulder height and width, elbow height, upper arm and arm length, and hand and forearm length), on the basis of which, together with the determination of characteristic operator working angles, the functional dimensions of the operators' bodies were obtained [42].

$\left(\mathrm{O}_{2}\right)$ Biomechanical-kinesiological measures. Based on measurements of the directions and times of the operators' hand movements, the maximum force was determined, with a previous determination of the mass of the operators' hands. By analysing the movements of the operators' left and right hands, head, eyes, and trunk (three times for 15 minutes each during shifts), their workloads were defined. 
$\left.\mathrm{(O}_{3}\right)$ Information search characteristics. An experimental investigation of the $\mathrm{CR}$ was used to form probability tables for whether an operator adequately responds to an information message. Based on those results, and applying the Bayesian rule, the amount of information passing through the monitored information channels was calculated.

$\left(\mathrm{O}_{4}\right)$ Operators' errors. The results of experimental studies of typical operator hand-movement errors in response to presented information signals led to the formation of a conditional probability of errors in the selection of a direction and choice of an arm, and the conditional probability of cumulative error.

$\left(_{5}\right)$ Operators and stress. To analyse the work of the operators in stressful situations, the operators' stress model was formed. The workplace stress scale is most commonly used to identify the causes of stress perception and stress coping capacity [42]. To obtain an assessment of the impact of stress on operators' activities, the effects of emergency situations and other stress factors on operators' work were analysed, and medical examinations were carried out with questionnaire surveys containing the Copenhagen Burnout Inventory and the Copenhagen Psychosocial Questionnaire [33].

(06) Operators' work activities. Based on the 24-hour monitoring of operators' work activities, a working diagram of the relative ability of the operators was formed, expressed as a percentage deviation from the daily average, and the daily load diagram of electric power distribution system (five-day monitoring).

( $\left.0_{7}\right)$ Mental models of operators' activities. A mental model of the operators' activities in emergency situations was formed and used to monitor a planning of probable events, prediction skills, workload management skills, and self-assessment activities. The mental workload assessment models applied to CR emergency situations were the Mental Workload Assessment and the Subjective Workload Assessment Technique [31].

$\left(\mathrm{O}_{8}\right)$ The training of electro-energetic system operators. Software packages were created for general education and for specialised user training programmes for operators in the electric power system.

\section{R) Control information system 'dispatch control room'}

$\left(r_{1}\right)$ Ergonomic analysis of display panels. The ergonomic analysis of the display panels consisted of coding of visual information; alphanumerical signs; the form of visual signs; and illumination, brightness, and contrast.

$\left(r_{2}\right)$ Visual search. An analysis of the dimensions of the display panel was determined on the size of the operators' view angles in relation to the coordinates of the endpoints of the display panel. The angular dimensions of the visual symbols on the display panel were analysed. For the proper construction of displays and the presentation of their signals, it was important to obtain the visual angle, which was defined by the following equation:

$$
\operatorname{tg} \frac{\alpha}{2}=\frac{S}{2 l},
$$

where $\mathrm{a}$ is the visual angle of a symbol, $\mathrm{S}$ is the linear dimension of a symbol, and $\mathrm{l}$ is the distance between an operator and the presented symbol.

$\left(r_{3}\right)$ Ergonomic characteristics of graphic screens. The ergonomic analysis of the video terminals (screen size, dimensions, symbols on the screen, the sensitivity of the screen, the screen brightness, the contrast between the screen and the symbol, the reflection on the screen, and the refresh rate of the screen) was done.

$\left(r_{4}\right)$ Control devices. We measured the initial forces that represent resistance in activating keys on the main keyboard and the switching buttons. The measurement relied on Avery scales, with an accuracy of measurement of $25 \mathrm{~g}$, and a measurement range of $0-10 \mathrm{~kg}$. The initial moment of the selectors was measured by the method of static load with declared weights.

$\left(r_{5}\right)$ Ergonomic characteristics of control desks. The control desk dimensions were measured, and on the basis of these results, the locations of the video display terminal, main keyboard, switching button, and screen on the desk were defined. The control desk working zones and the frequency of operators' engagements were defined for all working zones. 
$\left(r_{6}\right)$ Characteristic seat dimensions. The operators' working positions while seated were analysed, as well as the dimensions of the seats, the weight distribution during sitting, and the influence of the position of the backrest on the electrical activity of some back muscles and the pressure on the discs.

$\left(\mathrm{r}_{7}\right)$ The characteristics of accidents. The disintegration of the distribution system, emergency situations, obsolescence of the equipment, and device errors in the CR were analysed.

\section{E) Supporting system 'indoor environment'}

$\left(\mathrm{e}_{1}\right)$ Workplace organisation. A complete re-organisation of the workspace in the CR (video display terminal, display panel, control desk, etc.) was done, as well as of additional locations (computer equipment storage, locations for developers, equipment maintenance and repair facilities, lounges, etc.).

$\left(e_{2}\right)$ The analysis of noise. Noise measurement was performed for 12 hours at intervals of 15 minutes, using a precision sound level meter type 2209 and type 3143 Bruel and Kjaer microphone.

$\left(\mathrm{e}_{3}\right)$ The analysis of light conditions. Measuring the level and uniformity of the light sensitivity was carried out for the complete CR and at the workplaces using luxmeter Metrux-k, on the basis of the defined measurement plans.

$\left(\mathrm{e}_{4}\right)$ The analysis of the microclimate. Measurement of the microclimate conditions (temperature, relative humidity, and air velocity) was performed using a digital hygrometer $\mathrm{DH} 1$, thermometer Q510, mercury thermometers, and a tastoterm.

$\left(_{5}\right)$ Electromagnetic radiation. The radiation originating from a video display terminal, from its oscillatory circuits and electronic components, was measured (non-ionising radiation), and from the cathode ray tubes (ionising radiation).

$\left(\mathrm{e}_{6}\right)$ Colours scheme in the centre. Recommendations for the use of colours (for the ceiling, upper parts of the walls, the floor) in the CR were made. Specific reflection coefficients of the surfaces of the control panel and display panels were also defined, which were required to determine their luminosity.

$\left(\mathrm{e}_{7}\right)$ Quantification of the compatibility of man and the environment. The quantification of the compatibility of the operators and the CR elements was defined in matrix forms, based on availability and connectivity. A systems dynamics method was applied to specify interactions between the solutions related to the improvement of the working ability of an operator, a more humane and rational design of the control room elements, and improvements to the working conditions.

In order to assess the system efficiently, the selection and ranking of the key aspects of ergonomic research is needed.

\subsection{Identification of key aspects}

The ergonomic analysis of the electric power system operators' efficiency in the system 'operator-control room-working environment' was obtained. The identification of the most important aspects describing risk factors was obtained by the fuzzy AHP. To be able to reduce subjectivity during the analysis, a range of experts with different previous work experience were involved in the assessment $[7,45]$. The key risk factors were defined according to the research model (Figure 1). The basic elements on which the system was based (human system 'operator', control information system 'control room', and supporting system 'indoor environment') were used as criteria. The list of criteria and aspects describing risk factors is shown in Table 1.

The aspects were ranked by group FAHP, using triangular fuzzy numbers $M=(l, m, u)$. The hierarchy shown in Figure 1 was used. The following fuzzy scale was used during the pairwise comparison of elements: equal importance $(1,1,3)$, as well as weak $(1,3,5)$, strong $(3,5,7)$, demonstrated $(5,7,9)$, and absolute dominance $(7,9,9)$. 


\begin{tabular}{|c|c|}
\hline Criteria & Aspects \\
\hline $\begin{array}{l}\text { Human system } \\
\text { 'operator' (O) }\end{array}$ & $\begin{array}{l}\text { anthropometric measures }\left(O_{1}\right) \text {; biomechanical-kinesiological measures }\left(O_{2}\right) \text {; information } \\
\text { research characteristics }\left(O_{3}\right) \text {; operators' errors }\left(O_{4}\right) \text {; operators and stress }\left(O_{5}\right) \text {; operators' } \\
\text { work activities }\left(O_{6}\right) \text {; mental models of operators' activities }\left(O_{7}\right) \text {; the training of electro- } \\
\text { energetic system operators }\left(O_{8}\right)\end{array}$ \\
\hline $\begin{array}{l}\text { Control information } \\
\text { system 'control room' } \\
\text { (R) } \\
\text { Supporting system } \\
\text { 'indoor environment' } \\
\text { (E) }\end{array}$ & $\begin{array}{l}\text { Ergonomic analysis of display panels }\left(r_{1}\right) \text {; visual research }\left(r_{2}\right) \text {; ergonomic characteristics of } \\
\text { graphic screens }\left(r_{3}\right) \text {; control devices }\left(r_{4}\right) \text {; ergonomic characteristics of control desks }\left(r_{5}\right) \text {; } \\
\text { characteristic seat dimensions }\left(r_{6}\right) \text {; the characteristics of accidents }\left(r_{7}\right) \\
\text { Workplace organisation }\left(e_{1}\right) \text {; analysis of noise }\left(e_{2}\right) \text {; analysis of light conditions }\left(e_{3}\right) \text {; analysis } \\
\text { of microclimate }\left(e_{4}\right) \text {; electromagnetic radiation }\left(e_{5}\right) \text {; Colours in the centre }\left(e_{6}\right) \text {; } \\
\text { Quantification of the compatibility of man and the environment }\left(e_{7}\right)\end{array}$ \\
\hline
\end{tabular}

Three levels were identified. The main criteria for the research were human system ('operator'), control information system ('control room'), and supporting system ('indoor environment'). The results of pairwise comparisons were the weight vector of the criteria and the weight vector of the aspects for each criterion $[46,47]$.

The aggregation of the experts' opinions was based on the length of their professional career and the experts' experience with the specific system, represented by a gamma coefficient, as described by Grozdanovic et al. [7]. The row geometric mean method was used to obtain the weights of the individual experts [48] using the gamma coefficient. The crisp value was obtained by mean aggregated weight. The consistency was checked by the centric consistency index [49], with acceptable values proposed in research by Aguarón and Moreno-Jiménez [50].

\section{RESULTS}

The control room key performance indicators to be assessed were selected by six experts from the following fields: ergonomics, human reliability assessment, risk assessment, electric power systems, and mathematical modelling. The experts' years and level of experience were $B=\{17,16,28,13,23,12\}$ and $C=\{4,3,5,3,4,5\}$, defining the experts' weight vector $\Gamma=\{0.15,0.11,0.33,0.08,0.21,0.13\}$. The individual and aggregated judgement matrices for the criteria are presented in Tables 2 and 3 . The aggregation procedure was applied to obtain the ranks of aspects. Tables $4-6$ show the aggregated matrices for aspects compared with the criteria, where $\mathrm{CCl}$ is the centric consistency index.

Table 2: The matrices of individual experts for the criteria

\begin{tabular}{|c|c|c|c|c|}
\hline$D_{1}$ & & 0 & $R$ & $E$ \\
\hline \multirow{3}{*}{$y_{1}=0.15$} & 0 & $(1,1,1)$ & $(1 / 3,1 / 2,1)$ & $(1,2,3)$ \\
\hline & $R$ & $(1,2,3)$ & $(1,1,1)$ & $(1,2,3)$ \\
\hline & $E$ & $(1 / 3,1 / 2,1)$ & $(1 / 3,1 / 2,1)$ & $(1,1,1)$ \\
\hline \multirow{3}{*}{$\begin{array}{c}D_{2} \\
y_{2}=0.11\end{array}$} & 0 & $(1,1,1)$ & $(1 / 5,1 / 3,1)$ & $(3,5,7)$ \\
\hline & $R$ & $(1,3,5)$ & $(1,1,1)$ & $(1,2,3)$ \\
\hline & $E$ & $(1 / 7,1 / 5,1 / 3)$ & $(1 / 3,1 / 2,1)$ & $(1,1,1)$ \\
\hline \multirow{3}{*}{$\begin{array}{c}D_{3} \\
\gamma_{3}=0.33\end{array}$} & 0 & $(1,1,1)$ & $(1 / 3,1 / 2,1)$ & $(1,3,5)$ \\
\hline & $R$ & $(1,2,3)$ & $(1,1,1)$ & $(1,2,3)$ \\
\hline & $E$ & $(1 / 5,1 / 3,1)$ & $(1 / 3,1 / 2,1)$ & $(1,1,1)$ \\
\hline \multirow{3}{*}{$\begin{array}{c}D_{4} \\
y_{4}=0.08\end{array}$} & 0 & $(1,1,1)$ & $(1 / 5,1 / 3,1)$ & $(1,3,5)$ \\
\hline & $R$ & $(1,3,5)$ & $(1,1,1)$ & $(1,1,3)$ \\
\hline & $E$ & $(1 / 5,1 / 3,1)$ & $(1 / 3,1,1)$ & $(1,1,1)$ \\
\hline \multirow{3}{*}{$\begin{array}{c}D_{5} \\
\gamma_{5}=0.21\end{array}$} & 0 & $(1,1,1)$ & $(1 / 3,1 / 2,1)$ & $(1,2,3)$ \\
\hline & $R$ & $(1,2,3)$ & $(1,1,1)$ & $(1 / 3,1,1)$ \\
\hline & $E$ & $(1 / 3,1 / 2,1)$ & $(1,1,3)$ & $(1,1,1)$ \\
\hline \multirow{3}{*}{$\begin{array}{c}D_{6} \\
y_{6}=0.13\end{array}$} & 0 & $(1,1,1)$ & $(1,2,3)$ & $(1 / 3,1 / 2,1)$ \\
\hline & $R$ & $(1 / 3,1 / 2,1)$ & $(1,1,1)$ & $(1 / 5,1 / 4,1 / 3)$ \\
\hline & $E$ & $(1,2,3)$ & $(3,4,5)$ & $(1,1,1)$ \\
\hline
\end{tabular}

Table 3: The aggregated matrix for the criteria $(\mathrm{CCl}=0.07)$

\begin{tabular}{lllll}
\hline & $O$ & $R$ & $E$ & Mean \\
\hline$O$ & $(1,1,1)$ & $(0.35,0.55,1.15)$ & $(0.98,2.18,3.52)$ & 0.35 \\
$R$ & $(0.87,1.81,2.88)$ & $(1,1,1)$ & $(0.65,1.26,1.81)$ & 0.40 \\
$E$ & $(0.28,0.46,1.02)$ & $(0.55,0.8,1.54)$ & $(1,1,1)$ & 0.25 \\
\hline
\end{tabular}


Table 4: The aggregated matrix for the human system $(\mathrm{CCl}=0.05)$

\begin{tabular}{|c|c|c|c|c|c|c|c|c|c|}
\hline & $0_{1}$ & $\mathrm{O}_{2}$ & $\mathrm{O}_{3}$ & 04 & $O_{5}$ & $0_{6}$ & 07 & $O_{8}$ & Mean \\
\hline$o_{1}$ & $(1,1,1)$ & $(0.7,1.53,1.93)$ & $(0.24,0.34,0.67)$ & $(0.21,0.29,0.49)$ & $(0.2,0.27,0.46)$ & $(0.45,0.59,1.26)$ & $(0.45,0.72,1.38)$ & $(0.48,0.72,1.26)$ & 0.09 \\
\hline $\mathrm{O}_{2}$ & $(0.52,0.65,1.43)$ & $(1,1,1)$ & $(0.23,0.28,0.39)$ & $(0.19,0.25,0.42)$ & $(0.17,0.22,0.32)$ & $(0.27,0.43,0.85)$ & $(0.62,0.92,1.76)$ & $(0.51,0.86,1.61)$ & 0.07 \\
\hline $\mathrm{O}_{3}$ & $(1.18,2.64,3.92)$ & $(2.13,3.2,4.19)$ & $(1,1,1)$ & $(0.77,0.93,2.13)$ & $(0.44,0.68,1.26)$ & $(0.55,0.69,1.45)$ & $(0.55,0.91,1.53)$ & $(0.62,0.96,1.59)$ & 0.16 \\
\hline $\mathrm{O}_{4}$ & $(2.02,3.41,4.7)$ & $(2.36,3.98,5.16)$ & $(0.47,1.07,1.3)$ & $(1,1,1)$ & $(0.45,0.86,1.27)$ & $(1.8,2.78,3.63)$ & $(2.13,3.3,4.34)$ & $(1.8,2.86,3.84)$ & 0.17 \\
\hline $\mathrm{O}_{5}$ & $(2.19,3.73,5.1)$ & $(3.14,4.61,6.01)$ & $(0.79,1.48,2.28)$ & $(0.79,1.16,2.24)$ & $(1,1,1)$ & $(1.02,2.61,4.09)$ & $(2.75,3.99,5.09)$ & $(2.45,3.7,4.72)$ & 0.19 \\
\hline$O_{6}$ & $(0.79,1.68,2.24)$ & $(1.18,2.35,3.71)$ & $(0.69,1.45,1.8)$ & $(0.28,0.36,0.55)$ & $(0.26,0.41,1.01)$ & $(1,1,1)$ & $(1.01,2.26,3.4)$ & $(1.02,1.65,2.76)$ & 0.12 \\
\hline $0_{7}$ & $(0.72,1.39,2.24)$ & $(0.57,1.09,1.61)$ & $(0.65,1.1,1.81)$ & $(0.23,0.3,0.47)$ & $(0.2,0.25,0.36)$ & $(0.29,0.44,1.01)$ & $(1,1,1)$ & $(0.51,1.02,1.32)$ & 0.09 \\
\hline $\mathrm{O}_{8}$ & $(0.79,1.4,2.07)$ & $(0.62,1.17,1.96)$ & $(0.63,1.04,1.61)$ & $(0.26,0.35,0.55)$ & $(0.21,0.27,0.41)$ & $(0.36,0.6,0.99)$ & $(0.76,0.98,1.97)$ & $(1,1,1)$ & 0.10 \\
\hline
\end{tabular}

Table 5: The aggregated matrix for the control information system $(\mathrm{CCl}=0.13)$

\begin{tabular}{|c|c|c|c|c|c|c|c|c|}
\hline & $r_{1}$ & $r_{2}$ & $r_{3}$ & $r_{4}$ & $r_{5}$ & $r_{6}$ & $r_{7}$ & Mean \\
\hline$r_{1}$ & $(1,1,1)$ & $(1.16,2.29,3.3)$ & $(1.07,1.7,2.33)$ & $(1.9,3.64,5.13)$ & $(0.34,0.63,0.85)$ & $(0.42,0.62,1.02)$ & $(0.29,0.38,0.58)$ & 0.18 \\
\hline$r_{2}$ & $(0.3,0.44,0.86)$ & $(1,1,1)$ & $(1.45,1.97,3.18)$ & $(0.19,0.26,0.45)$ & $(0.16,0.2,0.26)$ & $(0.41,0.78,0.94)$ & $(0.31,0.49,0.65)$ & 0.09 \\
\hline$r_{3}$ & $(0.43,0.59,0.94)$ & $(0.31,0.51,0.69)$ & $(1,1,1)$ & $(1.11,1.18,2.73)$ & $(0.69,1.15,1.8)$ & $(0.38,0.48,0.82)$ & $(0.45,0.61,1.18)$ & 0.13 \\
\hline$r_{4}$ & $(0.2,0.28,0.53)$ & $(2.22,3.78,5.21)$ & $(0.37,0.85,0.9)$ & $(1,1,1)$ & $(0.36,0.51,1.12)$ & $(1.58,2.42,3.2)$ & $(1.45,2.28,3.05)$ & 0.12 \\
\hline$r_{5}$ & $(1.18,1.59,2.91)$ & $(3.78,4.96,6.06)$ & $(0.55,0.87,1.45)$ & $(0.89,1.95,2.75)$ & $(1,1,1)$ & $(1.4,2.91,4.24)$ & $(2.01,3.05,3.95)$ & 0.20 \\
\hline$r_{6}$ & $(0.98,1.62,2.35)$ & $(1.29,2.43,1.43)$ & $(1.43,2.07,2.62)$ & $(0.31,0.41,0.63)$ & $(0.25,0.37,0.79)$ & $(1,1,1)$ & $(1.65,2.46,3.22)$ & 0.14 \\
\hline$r_{7}$ & $(1.71,2.62,3.46)$ & $(1.53,2.04,3.25)$ & $(0.85,1.65,2.22)$ & $(0.33,0.44,0.69)$ & $(0.26,0.33,0.5)$ & $(0.31,0.41,0.61)$ & $(1,1,1)$ & 0.14 \\
\hline
\end{tabular}

Table 6: The aggregated matrix for the supporting system $(\mathrm{CCl}=0.1)$

\begin{tabular}{lllllllll}
\hline & \multicolumn{1}{c}{$\boldsymbol{e}_{1}$} & \multicolumn{1}{c}{$\boldsymbol{e}_{2}$} & \multicolumn{1}{c}{$\boldsymbol{e}_{3}$} & \multicolumn{1}{c}{$\boldsymbol{e}_{4}$} & \multicolumn{1}{c}{$\boldsymbol{e}_{5}$} & $\boldsymbol{e}_{6}$ & $\boldsymbol{e}_{7}$ \\
\hline $\boldsymbol{e}_{1}$ & $(1,1,1)$ & $(1.16,2.46,3.61)$ & $(0.18,0.24,0.38)$ & $(0.21,0.28,0.45)$ & $(0.24,0.37,0.85)$ & $(0.45,0.67,1.18)$ & $(0.32,0.44,0.73)$ & 0.09 \\
$\boldsymbol{e}_{2}$ & $(0.28,0.41,0.86)$ & $(1,1,1)$ & $(0.15,0.16,0.19)$ & $(0.22,0.29,0.57)$ & $(0.15,0.19,0.26)$ & $(0.38,0.78,1.19)$ & $(0.39,0.62,0.81)$ & 0.06 \\
$\boldsymbol{e}_{3}$ & $(2.91,4.25,5.49)$ & $(5.21,6.58,6.83)$ & $(1,1,1)$ & $(1.01,1.18,2.82)$ & $(1.01,1.65,2.61)$ & $(0.47,0.66,1.06)$ & $(0.5,0.71,1.23)$ & 0.23 \\
$\boldsymbol{e}_{4}$ & $(2.22,3.52,4.67)$ & $(1.76,3.4,4.86)$ & $(0.35,0.85,1)$ & $(1,1,1)$ & $(0.85,1.49,2.22)$ & $(1.45,2.28,3.05)$ & $(1.01,1.81,3.09)$ & 0.18 \\
$\boldsymbol{e}_{5}$ & $(1.18,2.73,4.09)$ & $(3.78,5.21,6.58)$ & $(0.38,0.61,1.02)$ & $(0.45,0.67,1.18)$ & $(1,1,1)$ & $(1.11,2.62,3.95)$ & $(1.4,2.78,3.95)$ & 0.17 \\
$\boldsymbol{e}_{6}$ & $(0.85,1.49,2.22)$ & $(0.85,1.29,2.62)$ & $(1.04,1.53,2.12)$ & $(0.33,0.44,0.69)$ & $(0.26,0.41,1.01)$ & $(1,1,1)$ & $(1.43,2.26,3.03)$ & 0.13 \\
$\boldsymbol{e}_{7}$ & $(1.36,2.29,3.15)$ & $(1.23,1.62,2.59)$ & $(0.81,1.4,2.01)$ & $(0.32,0.55,0.99)$ & $(0.25,0.36,0.71)$ & $(0.33,0.44,0.7)$ & $(1,1,1)$ & 0.14 \\
\hline
\end{tabular}


Table 7 shows the final rankings. For the $C R$ that was analysed, the most important aspects were the causes and effects of stress, the control desks, the display panels, and the lighting conditions.

Table 7: The rankings of key aspects

\begin{tabular}{|c|c|c|c|c|c|c|}
\hline & Aspect & $\begin{array}{l}0 \\
0.35\end{array}$ & $\begin{array}{l}R \\
0.40\end{array}$ & $\begin{array}{l}E \\
0.25\end{array}$ & $\begin{array}{l}\text { Aspect } \\
\text { weight }\end{array}$ & Rank \\
\hline$O_{1}$ & Anthropometric measures & 0.09 & & & 0.0300 & 19 \\
\hline $\mathrm{O}_{2}$ & Biomechanical-kinesiological measures & 0.07 & & & 0.0258 & 20 \\
\hline $\mathrm{O}_{3}$ & Information search & 0.16 & & & 0.0556 & 7 \\
\hline $\mathrm{O}_{4}$ & Operators' errors & 0.17 & & & 0.0574 & 6 \\
\hline $\mathrm{O}_{5}$ & Operators and stress & 0.19 & & & 0.0669 & 3 \\
\hline $\mathrm{O}_{6}$ & Operators' work activities & 0.12 & & & 0.0436 & 12 \\
\hline 07 & Mental models of operators' activities & 0.09 & & & 0.0346 & 17 \\
\hline $\mathrm{O}_{8}$ & The training of EES operators & 0.10 & & & 0.0358 & 15 \\
\hline$r_{1}$ & Ergonomic analysis of display panels & & 0.18 & & 0.0718 & 2 \\
\hline$r_{2}$ & Visual search & & 0.09 & & 0.0366 & 14 \\
\hline$r_{3}$ & Ergonomic characteristics of graphic screens & & 0.13 & & 0.0500 & 9 \\
\hline$r_{4}$ & Control devices & & 0.12 & & 0.0490 & 10 \\
\hline$r_{5}$ & Ergonomic characteristics of control desks & & 0.20 & & 0.0792 & 1 \\
\hline$r_{6}$ & Seat dimensions & & 0.14 & & 0.0546 & 8 \\
\hline$r_{7}$ & The characteristics of accidents & & 0.14 & & 0.0574 & 5 \\
\hline$e_{1}$ & Workplace organisation & & & 0.09 & 0.0230 & 21 \\
\hline$e_{2}$ & The analysis of noise & & & 0.06 & 0.0151 & 22 \\
\hline$e_{3}$ & The analysis of light conditions & & & 0.23 & 0.0576 & 4 \\
\hline$e_{4}$ & The analysis of microclimate & & & 0.18 & 0.0453 & 11 \\
\hline$e_{5}$ & Electromagnetic radiation & & & 0.17 & 0.0419 & 13 \\
\hline$e_{6}$ & The colours in the centre & & & 0.13 & 0.0334 & 18 \\
\hline$e_{7}$ & $\begin{array}{l}\text { Quantification of the compatibility of man } \\
\text { and the environment }\end{array}$ & & & 0.14 & 0.0354 & 16 \\
\hline
\end{tabular}

\section{4}

\section{DISCUSSION}

This section presents the discussion of the top four key aspects influencing the operators' work efficiency.

\subsection{Control desks}

Operators spend most of their working time at a control desk. It must be designed to provide the operator with the maximum comfort and the highest functionality. Unfortunately, most of the analysed control desks did not meet these criteria because, when these desks were designed, some of the ergonomic parameters were not taken into account.

The high video terminals that obscure the view of the display panels were identified as the major disadvantage of the control desks in the control rooms. The command desks in the control room are analysed below.

The desk in the CR is shown in Figure 2. It is polygonal, designed for two operators to work simultaneously. It consists of a flat plate and two branches for each operator, on which there are switching buttons for the telephone connection and the main keyboard for the formation of regulatory pools, which consists of a keyboard unit for the control of neighbouring areas and keyboard pools for the control of their own area of jurisdiction only.

The desk has the following characteristics: the height is $700 \mathrm{~mm}$; the depth is $100 \mathrm{~cm}$; the width at the zero point is $1130 \mathrm{~mm}$; and the horizontal section height is $630 \mathrm{~mm}$.

Only the desk width is greater than the recommended values [42]. According to the analysis of body movements during work, both hands are engaged only in the areas over $90^{\circ}$, which correspond with work zones D2 and D3. These work zones are unsuitable for frequent work, which further restricts the movement of other body parts. 


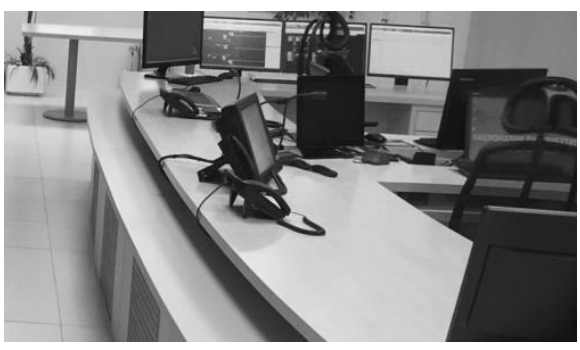

(a)

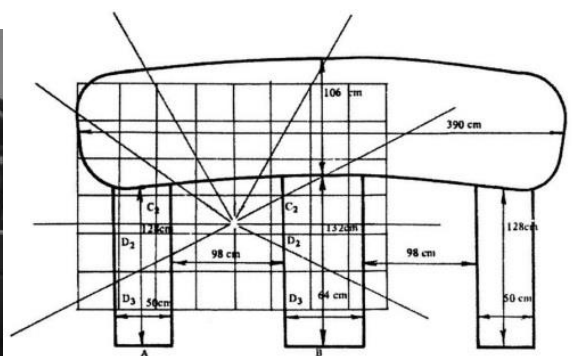

(b)

Figure 2: (a) The desk in the CR; (b) The desk dimensions

\subsection{Display panels}

The display panels are structurally implemented in order to reproduce the network topology of the electroenergetic system (EES) synoptically, displaying visual indications of the condition and functionality of the system being controlled and managed. Figure 3 shows the appearance of the main part of the control room for monitoring and control of the EES, and Figure 4 shows the dimensions of the display panels.

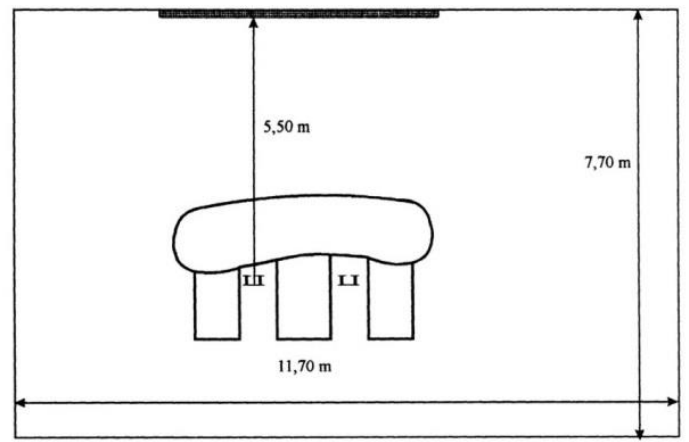

Figure 3: The control room

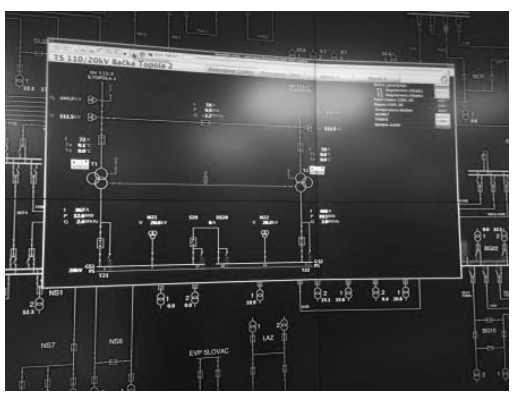

(a)

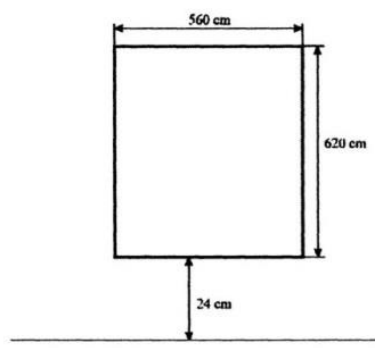

(b)

Figure 4: (a) The display panel in the control room; (b) The display panel dimensions

The values of the viewing angles (Table 8 ) were obtained according to the methodology presented by Grozdanovic [42]

Table 8: Values of the perceptible angles in the control room in relation to display panel height (hdp) and length (Idp)

\begin{tabular}{lllllll}
\hline \multirow{2}{*}{ hdp } & $\alpha_{1}(5)$ & $\alpha_{1}(50)$ & $\alpha_{1}(95)$ & $\alpha_{2}(5)$ & $\alpha_{2}(50)$ & $\alpha_{2}(95)$ \\
& $44^{\circ} 34^{\prime} 43^{\prime \prime}$ & $45^{\circ}$ & $44^{\circ} 48^{\prime} 15^{\prime \prime}$ & $-9^{\circ} 54^{\prime} 6^{\prime \prime}$ & $-10^{\circ} 30^{\prime} 22^{\prime \prime}$ & $-11^{\circ} 445^{\prime \prime}$ \\
\hline \multirow{2}{*}{ Idp } & $\gamma_{1}(5)$ & $\gamma_{1}(50)$ & $\gamma_{1}(95)$ & $\gamma_{2}(5)$ & $\gamma_{2}(50)$ & $\gamma_{2}(95)$ \\
& $18^{\circ} 59^{\prime} 45^{\prime \prime}$ & $19^{\circ} 7^{\prime} 31^{\prime \prime}$ & $19^{\circ} 10^{\prime} 32^{\prime \prime}$ & $35^{\circ} 7^{\prime} 30^{\prime \prime}$ & $35^{\circ} 19^{\prime} 21^{\prime \prime}$ & $35^{\circ} 23^{\prime} 56^{\prime \prime}$ \\
\hline
\end{tabular}


Based on the results of the visual angles presented for the fifth, fiftieth, and ninety-fifth percentiles, and their comparison with recommended values, we conclude the following:

- $\quad$ In the $\mathrm{CR}$, the height of the display panel should be reduced;

- The length of the display panel is inadequate, as the value of the angle is greater than recommended. However, one must account for the presence of another operator at the same control desk, as this would impair the adequacy of their visual angles.

On the display panel, the height of the instruments at the power transmission lines is $4.5 \mathrm{~cm}$, which is an acceptable dimension, because the distance between the operators and the panel is $l=550 \mathrm{~cm}$, and

$$
\alpha=2 \operatorname{arctg} \frac{S}{2 l}=2 \operatorname{arctg} \frac{4.5}{1100}=0.46^{\circ} \approx 28^{\prime} .
$$

However, the operator must follow the data presented on the scale of this instrument, which is much smaller in size; so this display is inadequate; and on the instruments displaying the totals, the scales have a small scope, and it is difficult to track the indication. Also, the printers below these instruments are inadequately lit, and flashing occurs.

\subsection{The causes and consequences of stressful situations}

In order to assess the impact of stress, its possible causes, and measures to reduce it, tests were conducted with the operators in the CR on the impact of accidental situations and other stress factors on their work. Medical checks of the CR operators were also analysed, in order to define the ergonomic recommendations to improve these situations.

The results from testing the operators identified the following causes of stress:

- Heavy dependence on telecommunication, measurement, and control technologies, especially during emergency situations;

- Constant nervous tension in anticipation of unforeseen events and possibilities of committing errors;

- Monitoring is done using a technologically obsolete information system, and there is not enough information for fast decision-making;

- $\quad$ The need for rapid and proper response in complex situations; no operational task can be postponed or transferred to others - it must be completed on time and accurately;

- $\quad$ The work is continuous, with day and night shifts that last twelve hours every day for a year. So the operators, in one calendar year, work about 25 per cent of their working time during the afternoon and 25 per cent during the night; and they also work on Saturdays and Sundays;

- Maximum concentration to memorise and monitor all events and data in the system is required when identifying alarm states;

- Inadequate training, which increases the possibility of an inadequate response, and ignoring the impact of neighbouring systems, can cause disturbances;

- Inadequate transition from a monotonous state to a state of intense work activity;

- The inadequacy of the workplace, because the efficiency of the operator and the number of errors significantly depends on its design and environment;

- Unnecessary communication through the operational channels: priorities need to be defined because, during hardware malfunctions, there is a much higher number of telephone calls (from journalists, various social and political organisations, and state bodies) that significantly interfere with the work of the operator during the first and most critical moments of re-establishing the power system;

- Unnecessary communication in the $\mathrm{CR}$, which should be kept to a reasonable level;

- The attitude of the operators to the consequences of stress on their health and ability to work was not specifically studied, but the medical examinations of the CR operators produced the following results. A group of operators (average age of 37.1 years; work experience of 12.8 years) was examined, and 13 of them had health problems. The most common problems related to nervous system and sensory organ diseases $(73.3 \%)$, followed by respiratory diseases $(56.6 \%)$, mental disorders $(30 \%)$, and circulatory system diseases (16.7\%). Among the individual diseases, the most common were damage to the cochlear nerve $(73.3 \%)$, respiratory diseases $(60 \%)$, refractive errors $(46.7 \%)$, and neurovegetative dystonia (NVD) $(33.3 \%)$.

The percentage of affected operators is large, with a high occurrence rate of certain diseases. These results should be carefully analysed; but owing to the lack of any detailed health status of the operators before 
the start of work, the findings cannot be attributed solely to the working conditions and requirements in the $\mathrm{CR}$.

Although the analysis is based on a relatively small number of operators, some alternative strategies for reducing the presence of stressful situations in the control room must be applied.

\subsection{Lighting conditions}

Lighting is a problem in most control rooms [42]. The measurements in the CR confirmed this conclusion.

A measurement of illuminance is performed according to the recommendations of Grozdanovic [42], based on the reduced plan of measurements at the operators' workplaces. The brightness and the uniformity of the light were measured in the entire CR (Table 9), and at the workplaces (Table 10), using the luxmeter Metrux k at a height of $0.85 \mathrm{~m}$ above the floor, and at the height of the work surfaces. Measuring the level of brightness was performed on the basis of defined measurement plans, and the results are shown in Table 10.

Table 9: The results of illuminance measurement in the entire CR

\begin{tabular}{cccc}
\hline Measurement point & Illuminance $(l \boldsymbol{x})$ & Measurement point & Illuminance $(\boldsymbol{l} \boldsymbol{x})$ \\
\hline 1 & 500 & 9 & 700 \\
2 & 410 & 10 & 280 \\
3 & 300 & 11 & 210 \\
4 & 70 & 12 & 115 \\
5 & 600 & 13 & 300 \\
6 & 390 & 14 & 150 \\
7 & 215 & 15 & 180 \\
8 & 95 & 16 & 75 \\
& & $E_{s r}$ & 286.9 \\
\hline
\end{tabular}

The recommendations require that the illumination at the least illuminated workplace be greater than 0.6 $E_{p r}$ (where $E_{p r}$ in our example is $250 \mathrm{~lx}$ ). From the results presented in Table 9 and Table 10, the CR does not meet these requirements.

To determine the illuminance uniformity, the ratio should be $E_{\min } / E_{s r}>0.4$. As the value of this ratio is 0.24 (70/286.9, Table 9) for the CR, we conclude that it does not meet the recommended values.

Table 10: The results of illuminance measurement at the workplaces

\begin{tabular}{clllll}
\hline The workplace & \multicolumn{5}{c}{ Illuminance (lx) } \\
\hline 1 & 390 & 430 & 310 & 155 & 220 \\
2 & 220 & 155 & 195 & 110 & 130 \\
$E_{s r}$ & 231.5 & & & \\
\hline
\end{tabular}

To ensure illumination uniformity, the ratio between the lowest level of illumination at the workplace and the medium illumination needs to be greater than 0.8 . As the value of this ratio is $0.48(110 / 231.5$, Table $10)$ for the $C R$, we conclude that this does not meet the requirements.

In order to define the luminance, the following factors of reflection are determined. In the $C R$, the desk is made of a brown veneer $(\rho=0.12)$. The panel has a medium yellow colour $(\rho=0.54)$.

The luminance in the CR is calculated as follows:

$$
\begin{gathered}
L_{k s}=\frac{0.12}{3.14} \cdot 231.5=8.85\left(\mathrm{~cd} / \mathrm{m}^{2}\right) \\
L_{p p}=\frac{0.54}{3.14} \cdot 342.5=58.90\left(\mathrm{~cd} / \mathrm{m}^{2}\right) \\
L_{k s} / L_{p p}=6.66
\end{gathered}
$$

The obtained values of luminance corresponded with the recommended values; and the illumination levels of the display panels, presented in Table 11, were derived from measurements in the CR. 
Table 11: The results of the measurement of the illuminance of the display panel in the CR

\begin{tabular}{cc}
\hline Measurement point & Illuminance $(\boldsymbol{l} \boldsymbol{x})$ \\
\hline 1 & 500 \\
\hline 2 & 370 \\
\hline 3 & 290 \\
\hline 4 & 210 \\
\hline
\end{tabular}

It is important to consider the illumination in the rooms in which operators work with video terminals (VDTs). The general conclusion is that the illumination of these rooms should be lower, as it would reduce unpleasant reflection from the screens, which is normally recommended for rooms without VDTs. Newer VDTs or monitors, which allow higher levels of illumination, together with new forms of indirect light source, would allow a higher level of illumination in the CR.

\section{CONCLUSION}

The design and the development of a control room in an electric power system is based on a number of criteria defined by the standards, work procedures, and characteristics of the processes being controlled. Based on the application of criteria in this study, operators' efficiency, the functional harmonisation of the $\mathrm{CR}$ and the operators, and the influence of the environment on the operators' work are evaluated. On the basis of the applied solutions from the results of the research conducted in this paper, this assessment provides recommendations for designing and developing new CRs and the reconstruction of the existing ones.

The proposed methodology allows the analysis of a CR by identifying key aspects based on the systems approach and the group FAHP method. Every aspect is described by a set of indicators. The method can be applied during the development of a new system or the analysis of an existing one. The key aspects of ranking identify the order (priority) during the CR development and/or improvement process. The FAHP method can be applied to the analysis of complex systems that are described by the hierarchical structure of indicators. The FAHP method can be applied to assess the model describing the system 'operator-control room-environment'. Owing to the complexity of the problem, one expert is not able to describe the system in the right way. Therefore a group decision-making method is applied. Fuzzy numbers allow the application of a range of values in the analysis, or to define a qualitative indicator for the range of values, that can help experts who are not familiar with the multi-criteria analysis to make a precise assessment.

During the analysis of the control room for electric power distribution monitoring and control, the following key aspects were identified: the control desk design, the display panel characteristics, the impact of stress, and the CR's lighting conditions. A desk redesign would remove the operators' inadequate movements. A different work organisation and presentation of important information would help operators to make the correct decisions in both normal and emergency situations. Based on the results obtained, we propose changes to enable better work positions for the operators, and a clearer presentation of the information on display panels and graphic screens.

The results of the research are not final solutions; they require constant improvements. Future research should therefore define a model of continuous improvement and control of ergonomic research results in the CR, supported by the latest ergonomic standards and recommendations.

\section{ACKNOWLEDGEMENT}

The research was supported by the Ministry of Education, Science and Technological Development of the Republic of Serbia.

\section{REFERENCES}

[1] Northcote-Green, J. \& Wilson, R.G. 2017. Electric power distribution systems. Boca Raton, USA: CRC Press.

[2] Panteli, M. \& Kirschen, D.S. 2015. Situation awareness in power systems: Theory, challenges and applications. Electric Power Systems Research, 122, pp. 140-151.

[3] Wu, F., Moslehi, K. \& Bose, A. 2005. Power system control centers: Past, present, and future. Proceedings of the IEEE, 93(11), pp. 1890-1908.

[4] Dos Santos, I.J.A.L., Farias, M.S., Ferraz, F.T., Haddad, A.N. \& Hecksher, S. 2013. Human factors applied to alarm panel modernization of nuclear control room. Journal of Loss Prevention in the Process Industries, 26(6), pp. 1308-1320. 
[5] Zhao, Y. \& Smidts, C. 2019. A method for systematically developing knowledge base of reactor operators in nuclear power plants to support cognitive modelling of operator performance. Reliability Engineering \& System Safety, 186, pp. 64-77.

[6] Grozdanovic, M. \& Bijelić, B. 2020. Impact of human, workplace and indoor environmental risk factors on operator's reliability in control rooms. Human and Ecological Risk Assessment: An International Journal, 26(1), pp. 177-189.

[7] Grozdanovic, M., Janackovic, G. \& Stojiljkovic, E. 2016. The selection of the key ergonomic indicators influencing work efficiency in railway control rooms. Transactions of the Institute of Measurement and Control, 38(10), pp. 1174-1185.

[8] Yih-Fang, H., Werner, S., Jing, H., Kashyap, N. \& Gupta, V. 2012. State estimation in electric power grids: Meeting new challenges presented by the requirements of the future grid. IEEE Signal Processing Magazine, 29(5), pp. 33-43.

[9] Meshkati, N. 2006. Safety and human factors considerations in control rooms of oil and gas pipeline systems: Conceptual issues and practical observations. International Journal of Occupational Safety and Ergonomics, 12(1), pp. 79-93.

[10] Weyers, B., Bowen, J., Dix, A. \& Palanque, P. 2017. The book of formal methods in human-computer interaction. Cham, Switzerland: Springer International Publishing AG.

[11] Ivergard, T. \& Hunt, B. 2019. Handbook of control room design and ergonomics: A perspective for the future, $2^{\text {nd }}$ ed. Boca Raton, USA: CRC Press, Taylor \& Francis Group.

[12] International Organization for Standardization (ISO). 2000. ISO 11064-1 - Ergonomic design of control centres Part 1: Principles for the design of control centres. Genève, Switzerland: ISO.

[13] International Organization for Standardization (ISO). 2019. ISO 9241-210 - Ergonomics of human-system interaction - Part 210: Human-centred design for interactive systems. Genève, Switzerland: ISO.

[14] International Organization for Standardization (ISO). 2016. ISO 6385 - Ergonomic principles in the design of work systems. Genève, Switzerland: ISO.

[15] Bedny, G.Z. \& Karwowski, W. 2019. Human-computer interaction and operators' performance: Optimizing work design with activity theory. Boca Raton, USA: CRC Press.

[16] Fan, J. \& Smith, A.P. 2018. A preliminary review of fatigue among rail staff. Frontiers in Psychology, 7(9), pp. 110.

[17] Rajabi-Vardanjani, H., Habibi, E., Pourabdian, S., Dehghan, H. \& Maracy, M.R. 2014. Designing and validation a visual fatigue questionnaire for video display terminals operators. International Journal of Preventive Medicine, 5(7), pp. 841-848.

[18] Manzey, D., Gerard, N. \& Wiczorek, R. 2014. Decision-making and response strategies in interaction with alarms: The impact of alarm reliability, availability of alarm validity information and workload. Ergonomics, 57(12), pp. 1833-1855.

[19] Wickens, C.D. \& Hollands, J.G. 2012. Engineering psychology and human performance, $4^{\text {th }}$ ed. London: Psychology Press Ltd.

[20] Salmon, P.M., Stanton, N.A., Walker, G.H., Jenkins, D., Baber, C. \& McMaster, R. 2008. Representing situation awareness in collaborative systems: A case study in the energy distribution domain. Ergonomics, 51(5), pp. 367384.

[21] Zare, M., Sagot, J.C. \& Roquelaure, Y. 2018. Within and between individual variability of exposure to workrelated musculoskeletal disorder risk factors. International Journal of Environmental Research and Public Health, 15(5), pp. 1-9, DOI:10.3390/ijerph15051003.

[22] Jun, S.H. \& Seong, P.H. 2009. A human-machine interface evaluation method: A difficulty evaluation method in information searching (DEMIS). Reliability Engineering \& System Safety, 94(10), pp. 1557-1567.

[23] Yetkin, M.E., Simsir, F., Ozfirat, M.K., Ozfirat, P.M. \& Yenice, H. 2017. A fuzzy approach to selecting roof supports in longwall mining. South African Journal of Industrial Engineering, 27(1), pp. 162-177.

[24] Park, K.S. \& Lee, J.I. 2008. A new method for estimating human error probabilities: AHP-SLIM. Reliability Engineering \& System Safety, 93(4), pp. 578-587.

[25] Markowski, A.S., Mannan, M.S. \& Bigoszewska, M.S. 2009. Fuzzy logic for process safety analysis. Journal of Loss Prevention in the Process Industries, 22(6), pp. 695-702.

[26] Meyer, M. \& Sunjka, B.P. 2019. A skill measurement model for the South African energy sector: Applying the analytic hierarchy process to the South African electric power industry. South African Journal of Industrial Engineering, 30(3), pp 277-288.

[27] Manca, D., Nazir, S., Lucernoni, F. \& Colombo, S. 2012. Performance indicators for the assessment of industrial operators. Computer Aided Chemical Engineering, 30, pp. 1422-1426.

[28] Guttromson, R.T., Schur, A., Greitzer, F.L. \& Paget, M. 2007. Human factors for situation assessment in power grid operations. Technical Report PNNL-16780. Richland, WA: Pacific Northwest National Laboratory.

[29] Chen, M., Catterson, V., Syed, M., Mcarthur, S., Burt, G., Marinelli, M., Prostejovsky, A.M. \& Heussen, K. 2017. Supporting control room operators in highly automated future power networks. CIRED - Open Access Proceedings Journal, 1, pp. 1492-1495.

[30] Grozdanovic. M. 2020. Interaction between an operator and the control desk at the control room of the railway traffic: A Serbian experience. Human Factors and Ergonomics in Manufacturing \& Service Industries, 30(3), pp. 221-234.

[31] Stanton, N., Salmon, P., Rafferty, L., Walker, G., Baber, C. \& Jenkins, D. 2013. Human factors methods: A practical guide for engineering and design. Boca Raton, USA: CRC Press, Taylor \& Francis Group.

[32] Stojiljkovic, E. 2020. Human reliability assessment. Monograph. Nis, Serbia: University of Nis, Faculty of Occupational Safety [in Serbian]. 
[33] Ilic, I., Arandjelovic, M., Jovanovic, J. \& Nesic, M. 2017. Relationships of work-related psychosocial risks, stress, individual factors and burnout - Questionnaire survey among emergency physicians and nurses. Medycyna Pracy, 68(2), pp. 167-178.

[34] Crandall, B., Klein, G. \& Hoffman, R.R. 2006. Working minds: A practitioner's guide to cognitive task analysis. Cambridge, MA: MIT Press.

[35] Tytyk, E. \& Mrugalska, B. 2018. Towards innovation and development in ergonomic design: Insights from a literature review. Procedia - Social and Behavioral Sciences, 238, pp. 167-176.

[36] Azadeh, A., Alizadeh Bonab, N., Salehi, V. \& Zarrin, M. 2015. A unique algorithm for the assessment and improvement of job satisfaction by resilience engineering: Hazardous labs. International Journal of Industrial Ergonomics, 49, pp. 68-77.

[37] Caputo, F., Greco, A., Fera, M. \& Macchiaroli, R. 2019. Workplace design ergonomic validation based on multiple human factors assessment methods and simulation. Production and Manufacturing Research, 7(1), pp. 195-222.

[38] Grozdanovic, M., Marjanovic, D. \& Janackovic, G. 2016. Control and management of coal mines with control information systems. The International Arab Journal of Information Technology, 13(4), pp. 387-394.

[39] Shi, X., Zhu, N. \& Zheng, G. 2013. The combined effect of temperature, relative humidity and work intensity on human strain in hot and humid environments. Building and Environment, 69, pp. 72-80.

[40] DiLaura, D.L., Houser, K.W., Mistrick, R.G. \& Steffy, G.R. 2011. The lighting handbook: Reference and application. New York: Illuminating Engineering Society of North America.

[41] Piňosová, M., Andrejiová, M. \& Lumnitzer, E. 2018. Synergistic effect of risk factors and work environmental quality. Quality - Access to Success, 19(165), pp. 154-159.

[42] Grozdanovic, M. 2003. Ergonomic design of control and managing centers of automated systems. Nis, Serbia: University of Nis [in Serbian].

[43] Charmode, S.H. \& Kadlimatti, H.S. 2019. Correlation of foot dimensions with body weight - A study in young population of central India. Translational Research in Anatomy, 16, pp. 1-6.

[44] Charmode, S.H., Kadlimatti, H.S. \& Pujari, D. 2019. Correlation of human height with hand dimensions: A study in young population of central India. International Journal of Human Anatomy, 1(3), pp. 36-44.

[45] Tsyganok, V.V., Kadenko, S.V. \& Andriichuk, O.V. 2012. Significance of expert competence consideration in group decision making using AHP. International Journal of Production Research, 50(17), pp. 4785-4792.

[46] Deng, H. 1999. Multicriteria analysis with fuzzy pairwise comparison. International Journal of Approximate Reasoning, 21(3), pp. 215-231.

[47] Janackovic, G., Stojiljkovic, E. \& Grozdanovic, M. 2020. Selection of key indicators for the improvement of occupational safety system in electricity distribution companies. Safety Science, 125, pp. 1-7, DOI:10.1016/j.ssci.2017.07.009.

[48] Crawford, G. \& Williams, C. 1985. A note on the analysis of subjective judgment matrices. Journal of Mathematical Psychology, 29(4), pp. 387-405.

[49] Bulut, E., Duru, O., Keçeci, T. \& Yoshidaa, S. 2012. Use of consistency index, expert prioritization and direct numerical inputs for generic fuzzy-AHP modeling: A process model for shipping asset management. Expert Systems with Applications, 39(2), pp. 1911-1923.

[50] Aguarón, J. \& Moreno-Jiménez, J.M. 2003. The geometric consistency index: Approximated thresholds. European Journal of Operational Research, 147(1), pp. 137-145. 